\title{
The impact of a cartoon character on adults perceptions of Children's breakfast cereals: a randomized experiment
}

\author{
Alejandra Contreras-Manzano ${ }^{1}$, Alejandra Jáuregui ${ }^{1 *}$ (D), Claudia Nieto ${ }^{1}$, Marissa G. Hall², Jorge Vargas-Meza', \\ James F. Thrasher ${ }^{3,4}$, Daniel Illescas-Zárate ${ }^{1}$, Simón Barquera ${ }^{1}$ and David Hammond ${ }^{5}$
}

\begin{abstract}
Background: Cartoon characters on processed food packaging increase the perception of product preference among children, but their effect among adults has rarely been examined. We evaluated the effect of a cartoon character on breakfast cereals on beliefs about buying them for children, as well as whether demographic characteristics modified this effect.

Methods: An experimental study was conducted with adults from online consumer panels in Mexico $(n=3755)$. Participants were randomly assigned to a "cartoon" condition $(n=1789)$, in which they viewed a breakfast cereal box with a Minion character on the front of the package, or the "control" condition $(n=1966)$, in which the same cereal box was displayed with no character on the package. Participants were asked: "Is this a good cereal to buy children?" with the response options "Yes", "No", or "Don't know". Multinomial adjusted logistic models regressed responses to this question (Yes $=0, \mathrm{No}=1,2=$ Don't know) on experimental condition. Differences in the effect of the cartoon character across demographic characteristics were tested by introducing multiplicative interaction terms.

Results: The adjusted model showed that participants in the "cartoon character" condition were 1.67 (1.45-1.94) times more likely to consider the cereal as being "Not good to buy for children" than those in the control condition $(p<0.001)$. This effect was smaller among parents (RRR $=1.39,1.13-1.72)$ compared to those without children (RRR $=2.01,1.63-2.47)$. No differences were observed in the proportion of participants answering "Don't know" across experimental groups.

Conclusion: Among this sample of Mexican adults, a cereal with a cartoon character on the packaging was more often perceived as "not good to buy for children" compared to a cereal without it. This effect was smaller among parents, potentially due to children influences of parental decisions during food purchasing.
\end{abstract}

Keywords: Cartoon characters, Marketing directed to children, Goodness perception

\footnotetext{
* Correspondence: alejandra.jauregui@insp.mx

${ }^{1}$ Nutrition and Health Research Center, Mexican National Institute of Public Health, Av. Universidad 655 Col, Santa María Ahuacatitlán, 62100 Cuernavaca, Mexico

Full list of author information is available at the end of the article
}

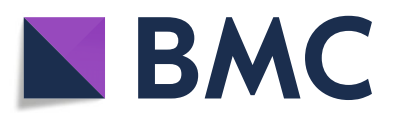

(- The Author(s). 2020 Open Access This article is licensed under a Creative Commons Attribution 4.0 International License, which permits use, sharing, adaptation, distribution and reproduction in any medium or format, as long as you give appropriate credit to the original author(s) and the source, provide a link to the Creative Commons licence, and indicate if changes were made. The images or other third party material in this article are included in the article's Creative Commons licence, unless indicated otherwise in a credit line to the material. If material is not included in the article's Creative Commons licence and your intended use is not permitted by statutory regulation or exceeds the permitted use, you will need to obtain permission directly from the copyright holder. To view a copy of this licence, visit http://creativecommons.org/licenses/by/4.0/. The Creative Commons Public Domain Dedication waiver (http://creativecommons.org/publicdomain/zero/1.0/) applies to the data made available in this article, unless otherwise stated in a credit line to the data. 


\section{Background}

Mexico has one of the highest prevalence of childhood obesity worldwide [1-3]. Consumption of discretionary foods, like breakfast cereals that contain high amounts of saturated fat and/or added sugar, is a major contributor to childhood obesity [4-6]. These discretionary foods represent $25 \%$ of daily caloric intake among Mexican school-aged children and adolescents [7]. Most breakfast cereals available in the Mexican market (69\%) in 2014 were classified as "less healthy" according the United Kingdom Nutrient Profiling Model [8]. Furthermore, in Mexico, ready-to-eat breakfast cereals provide $7 \%$ of the total energy intake among Mexican preschoolers [9].

The food industry often uses cartoon characters on their product packaging to heighten appeal among children. Socio-cognitive theories and interaction models suggest that children tend to have positive associations with familiar and likable characters. The positive feelings associated with these characters will transfer to the product or brand, increasing brand preference, loyalty, and recognition $[10,11]$. Indeed, it has been widely documented that in children and youth, cartoon characters on product packaging attract more attention, $[12,13]$ increase products' appeal, [5] and even change perceptions of product taste [6].

A review of literature of eleven studies published between 2004 and 2014 conducted mainly in the USA and European countries reported that cartoon characters may increase children's appetite, preference for, choice and intake of foods compared with no character branding, especially for energy dense and nutrient-poor foods (e.g. cookies, candy or chocolate) [11]. Studies suggest that cartoon characters help children recognize the brand, [14] and aim to create a positive attitude and loyalty towards the product [15-17]. Recently, the European Consumer Organization stated a position which calls for food manufacturers to stop marketing strategies like the use of brand mascots and licensed media characters marketed to children [18].

However, the effect of cartoon characters on the front of the pack of processed foods among adults is scarce. A study among Canadian parents reported that although they considered products with a cartoon character as more appealing than those without them, they perceived products with a cartoon character as of lower nutritional quality when compared to products with a front-of-pack nutritional label or a cartoon character plus a front-of-pack nutritional label [19]. Parents may be persuaded to buy food products by two factors: 1) perceived product healthfulness inferred from the nutrition information on the package, and 2) their children preferences - which are strongly influenced by cartoon characters - even when the food content may not be nutritious at all [19-21]. Nonetheless, to our knowledge, no study has explored the effect of cartoon characters among non-parents.
Further, studies have reported that the use of nutritional information on the front-of-the pack, such as the front-of-pack nutrient labeling, is higher among females, older adults, those with higher income and education levels, those with a health condition or being the primary shopper of the household [22-24] Based on this evidence, it could be hypothesized that a cartoon character displayed on the front-of-the pack could have a differential effect across groups of people with different individual characteristics. Therefore, the aim of this study was to explore the impact of a cartoon character on Mexican adult consumers' belief that breakfast cereals are good to buy for children and if individual characteristics, such as having children, modified this effect.

\section{Material and methods}

We analyzed data from the Mexico administration of the first wave of the International Food Policy Study, a crosssectional survey of adults aged $18-65$ years $(n=19,857)$ from five countries, including Mexico, who completed an online questionnaire in December 2017. The survey assessed seven primary policy domains: price/taxation, food packaging and labeling, retail food policies, food marketing (including the current experiment), nutritional labeling in restaurants, nutrition information and education, and food guide/dietary recommendations.

The study sample was recruited via Nielsen Consumer Insights Global Panel and their partners' panels. The panels were originally recruited using both probability and non-probability sampling methods in each country. Nielsen drew stratified random samples from the online panels in each country, based on known proportions in each age group. Individuals were eligible to participate if they were 18-64 years of age and resided in the target country.

In Mexico, a total of 68,336 email invitations (with a unique link) were sent to a random sample of panelists (after targeting for age). Participation rate was 6.2\% ( $n=$ 4268). All potential respondents were provided with information about the study and were asked for an informed consent prior to completing an online survey.

Most survey items were adapted from national surveys and prior studies. Native Spanish-speakers verified the accuracy of the translation of survey items from English to Spanish. The mean survey time was $42 \mathrm{~min}$. Respondents received compensation in accordance with their panel's usual incentive structure (e.g., points-based or monetary rewards, chances to win prizes). The study was reviewed by and received ethics clearance through a University of Waterloo Research Ethics Committee (ORE\# 21460). A full description of the study methods can be found in the International Food Policy Study: Technical Report - Wave 1 (2017) at http://www.foodpolicystudy.com/methods. 


\section{Cartoon character experiment}

Researchers selected an image of a cartoon character commonly used in products marketed to children in Mexico. The Minion character, a computer animated character, became popular from the movies released in Mexico in the years of 2010, 2013, 2015, and 2017.

Participants were randomly assigned to the "Cartoon condition", that was a ready-to-eat breakfast cereal box with the Minion character on the front of the package, or the "Control" condition that was the same cereal box with no character on the front of the package (Fig. 1). The cereal box displayed a fabricated brand to control for established beliefs about cereal brands. Guideline Daily Allowances, the mandatory front-of-pack label in Mexico, were displayed on the boxes. However, the label was intentionally small and blurred to prevent consumers from reading it. The assigned image was displayed on screen and participants were asked: "Is this a good cereal to buy children?" with the response options "Yes", "No" or "Don't know".

\section{Sociodemographic characteristics}

Sociodemographic characteristics included age (categorical), gender (male/female), ethnicity (minority/majority), parental status (no children or having children), education level (high school or lower/technical school/university degree or higher), and region of the country (North/South/ Centre/Mexico City). Income was assessed with the question "Thinking about your total monthly income, how difficult or easy is it for you to make ends meet?", with responses collapsed into "very difficult or difficult", "neither easy nor difficult", and "easy or very easy".

\section{Other measures relevant to food choices}

Self-reported nutrition knowledge was assessed with the question "How would you rate your nutrition knowledge?", with responses collapsed into not knowledgeable ("not at all knowledgeable" and "a little knowledgeable"), somewhat knowledgeable, and knowledgeable ("very knowledgeable" and "extremely knowledgeable").

Front-of-pack label understanding was assessed with the question "how difficult or easy is it to identify unhealthy foods using food labels?", with answer options collapsed into "Very difficult or difficult", "Neither difficult or easy" and "Easy or very easy". Front-of-pack label use was assessed with the question "how often do you use nutrition information on food labels when deciding to buy a food product?" with responses recoded to "never or rarely", "sometimes" and "most of the time or always".

Label influence in food choice was assessed with the question "Overall, how much do food labels influence what you eat?", with answer options collapsed into "no influence or a little influence", and "some or a lot of influence".

Daily calorie counting was assessed by asking "Do you count calories you consume each day?" and answer options were collapsed into "never or rarely" and "sometimes or most of the time".

\section{Data analysis}

A total of 4057 adults completed the survey. For the primary outcome, participants were classified as considering the cereal as "Good to buy for children" (answered "Yes"), "Not good to buy for children" (answered "No") and "Don't know" (answered "Don't know"). We removed from the analysis participants with missing data in the outcome $(n=19)$, demographics (e.g., parental status, income adequacy) $(n=110)$ or other measures relevant to food choices (e.g., nutrition knowledge, label use, counting calories) $(n=173)$. This decision was made based on preliminary results showing that randomization

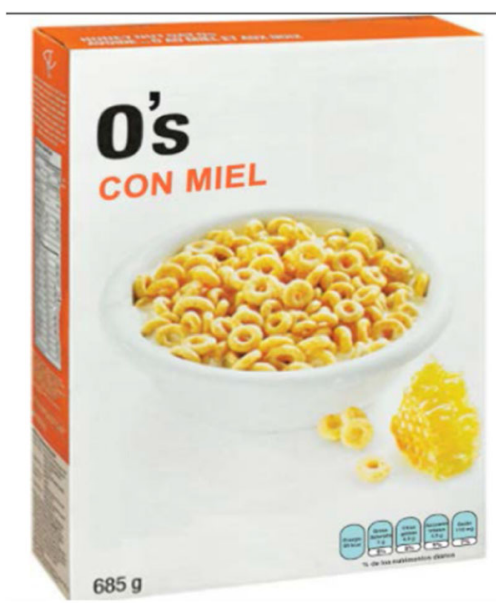

a

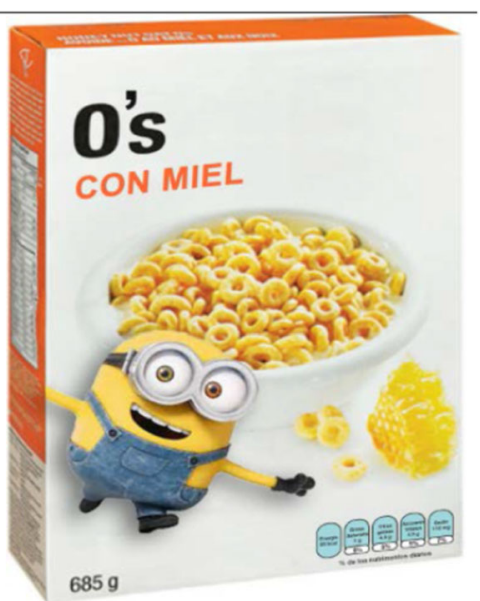

b

Fig. 1 Breakfast cereal shown in the experiment. a) Control b) Cartoon 
was not successful in creating comparable groups. Thus, all models were adjusted for demographic variables and other measures related to food choices. The proportion of participants removed did not differ across experimental conditions (Control group; $n=148$ and Cartoon group: 154, $p=0.252$ ). A total sample of 3755 (Control: 1966; Cartoon: 1789) participants were included in the analyses.

We compared demographic characteristics and information relevant to food choices by experimental condition using $\mathrm{t}$-tests for continuous variables and Chi-square tests for categorical variables. We estimated multinomial logistic regression models to estimate the relative risk ratios (RRR) for considering the breakfast cereal as "Good to buy for children", "Not good to buy for children" or responding "Don't know" across experimental conditions (cartoon character or control). Models were adjusted for age, gender, ethnicity, parental status, education level, region of the country, income adequacy, self-reported nutrition knowledge, front-of-pack label understanding, use, and influence on purchasing decisions and daily calorie counting.

Based on previous literature showing differences in the use of nutritional information on the front-of-the pack of processed foods [22-24], we aimed to explore if the effect of the cartoon character differed across specific groups of participants (i.e. gender, age group, health status, education level, parental status, income adequacy, nutritional knowledge and front-of-pack label understanding, use and influence on food purchasing decisions). Separate regression models were used to estimate differences in the associations between socio-demographic correlates and the outcome. Multiplicative interactions between individual characteristics and experimental condition (e.g. experiment group $\mathrm{x}$ gender) were entered individually into the base model and interactions that were significant at a level of $p<0.05$ were then entered into the base model simultaneously. Interactions that were not significant at $p<0.05$ from the multivariable model were removed, leaving only significant interactions in the final interaction model. Stratified models are presented if the interaction term was significant at a level of $p<0.05$. Analysis were conducted using Stata SE v14.

\section{Results}

Table 1 shows the characteristics of participants by experimental condition. Experimental groups were comparable in most of their characteristics, except for income adequacy in the subgroup "Difficult" (Control: $38.6 \%$ vs Cartoon: $40 \%$ ) and "neither difficult nor easy" (Control: $41.4 \%$ vs cartoon: $37.4 \%, p=0.029$ ), and for label understanding in the subgroups "neither difficult nor easy" (control: $35.1 \%$ vs cartoon $31.1 \%$ ) and "easy or very easy" (control: $34.8 \%$ vs cartoon: $38.8 \%$ ).

The mean age was 33.8 years $(\mathrm{SD}=0.26)$ in the Control group and 34.0 years $(\mathrm{SD}=0.27)$ in the Cartoon group. Participants were evenly distributed among males and females; and between those having and those not having children. Most participants were non-indigenous (87.4\%), $49.7 \%$ were parents, nearly $70 \%$ had a university degree or higher, $32.4 \%$ lived in the Center of the country, $54.7 \%$ reported to be somewhat nutrition knowledgeable, around $70 \%$ considered labels had some or a lot of influence in food choices, and nearly $70 \%$ never counted calories.

Table 2 shows the proportions and relative risk ratios for considering the breakfast cereal "good to buy for children", "not good to buy for children" or responding "don't know" across experimental conditions. A total of $54.8 \%$ of participants considered the breakfast cereal as "Good to buy for children" when the box did not display a cartoon character; meanwhile, this figure was of $45.5 \%$ when the box displayed a cartoon character. In contrast, $28.9 \%$ of participants considered the breakfast cereal as "Not good to buy for children" in the control group, whereas this proportion was of $39.4 \%$ in the cartoon character group. The proportion of participants answering "Don't know" was similar across experimental groups (Control box: $16.3 \%$, Minion box: $15.1 \%)$.

The adjusted model showed that participants who viewed a cereal box with a cartoon character were 1.67 (1.45-1.94) times more likely to consider the cereal as being "Not good to buy for children" relative to those who viewed a control cereal box (Table 2).

The interaction model showed that this effect was different across parental status categories (Interaction term RRR: 1.39, $p=0.029$ ) (Supplementary Table 1). The stratified model across parental status showed that nonparents assigned to the cartoon condition were 2.01 $(1.63,2.47)$ times more likely to consider the cereal box as "Not good to buy for children" compared to those assigned to the Control condition, whereas this effect was significantly smaller among parents $(R R R=1.39$, $(1.13,1.72])$ (Table 2). No differences were observed in the proportion of participants answering Don't know across experimental groups in any of the models.

\section{Discussion}

In this experiment, we tested the impact of a cartoon character on Mexican adult consumers' belief that breakfast cereals are good to buy for children and if individual characteristics modified this effect. We found that Mexican adults who viewed a cereal box with a cartoon character were more likely to consider the cereal as "not good to buy for children" compared to those who viewed the same cereal box without the cartoon character. This effect was stronger among non-parents compared to parents. 
Table 1 Comparison of sociodemographic characteristics and other measures relevant to food choices among the overall sample and across parental status condition $(n=3755)$

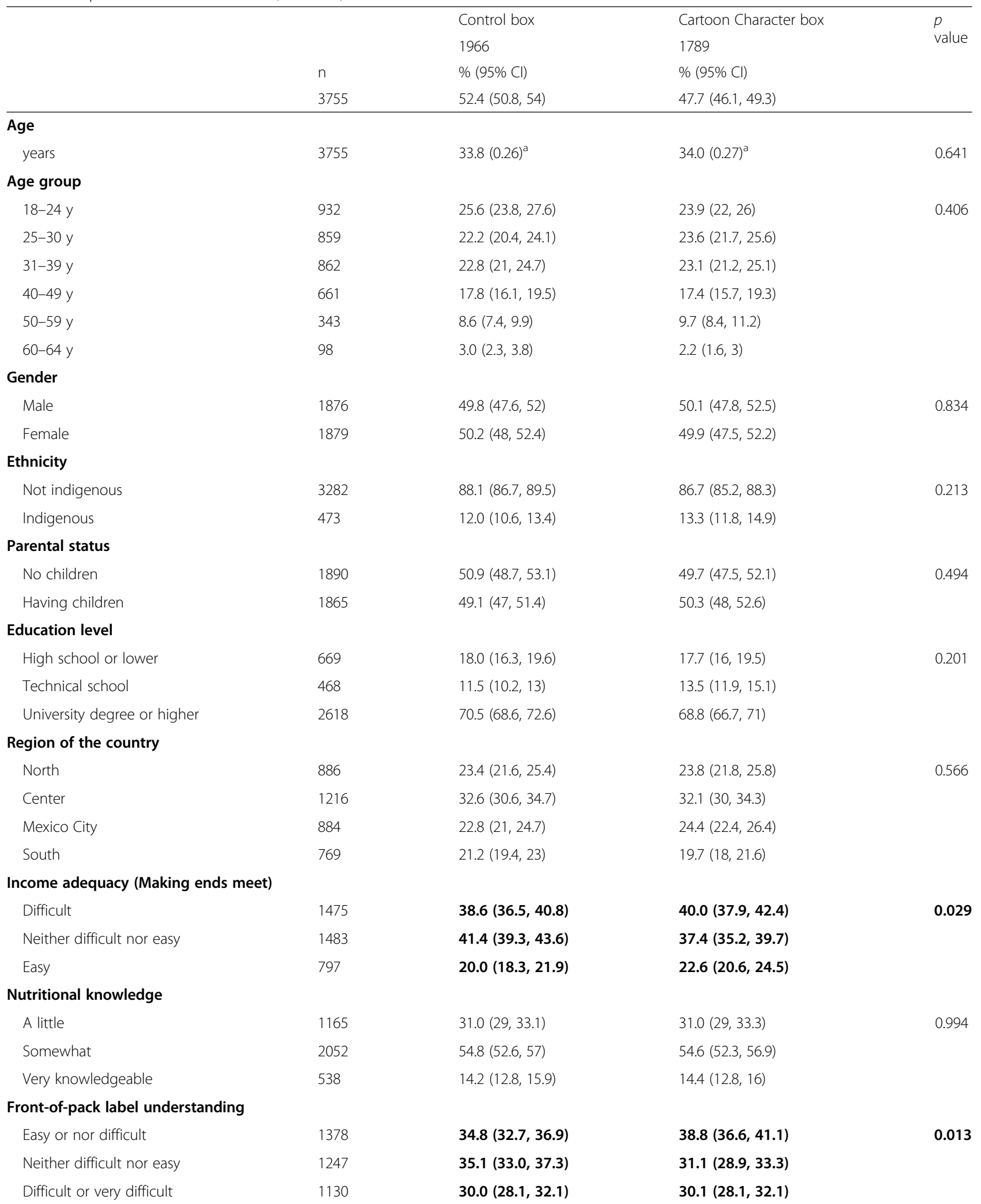


Table 1 Comparison of sociodemographic characteristics and other measures relevant to food choices among the overall sample and across parental status condition $(n=3755)$ (Continued)

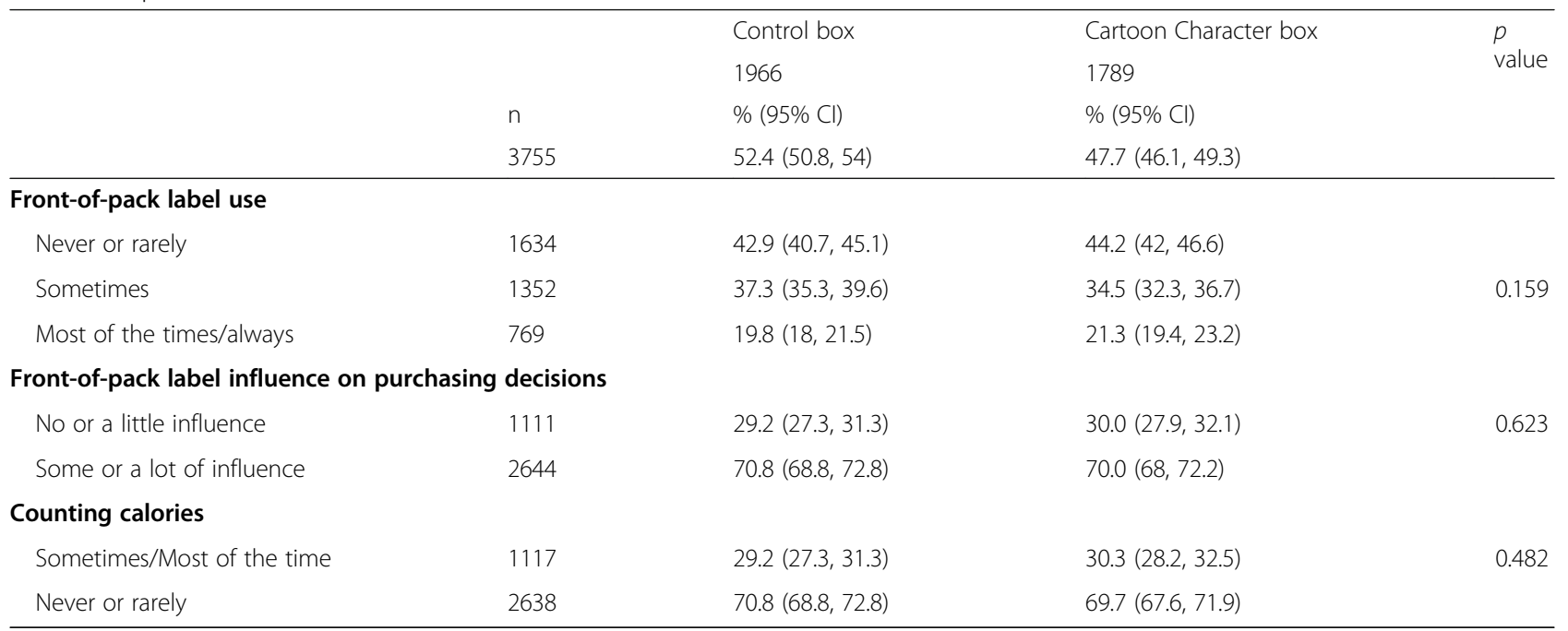

Differences were tested using Chi-square tests or t-student test for age in years. $\mathrm{Cl}=$ Confidence Interval

${ }^{a}$ Mean (S.D.)

Cartoon characters are effective in influencing children's food preferences, choices and intake, especially for energy-dense and nutrient-poor foods compared with fruits or vegetables [11]. However, few studies have explored the effect of cartoon cereals among adult populations. A study among Canadian parents reported that products with a cartoon character were perceived as of lower nutritional quality when compared to products without these characters [19]. In line with these results, our study showed that cartoon cereals increased the odds of considering the cereal as "not good to buy for children". Interestingly, this effect was smaller among parents. Differences in the effect between parents and non-parents might be due to the subjective understanding of "good". It is probable that among parents this word was interpreted as "accepted", "appealing" or "tasty" for their children, instead of "healthy" for children. However, we believe this explanation is rather unlikely given that in Spanish the word "good" describing a food is generally used for "positive value", "high quality",

Table 2 Proportions and adjusted" relative risk ratios (RRR) for considering the breakfast cereal as "Not good to buy for children" or answering "Don't know" among the overall sample and across parental status condition $(n=3755)$

\begin{tabular}{|c|c|c|c|c|}
\hline & \multicolumn{2}{|l|}{$\begin{array}{l}\text { Control } \\
\text { Box }\end{array}$} & \multicolumn{2}{|c|}{$\begin{array}{l}\text { Cartoon Character } \\
\text { Box }\end{array}$} \\
\hline & n (\%) & RRR & n (\%) & RRR $(95 \% \mathrm{Cl})$ \\
\hline Overall sample $(n=3755)$ & $1966(100)$ & & $1789(100)$ & \\
\hline Good & $1077(54.8)$ & 1.00 & $814(45.5)$ & 1.00 \\
\hline Not good & $569(28.9)$ & 1.00 & $704(39.4)$ & $1.67(1.45,1.94)$ \\
\hline Don't know & $320(16.3)$ & 1.00 & $271(15.1)$ & $1.15(0.95,1.39)$ \\
\hline Parents $(n=1865)$ & $966(100)$ & & $899(100)$ & \\
\hline Good & $543(56.2)$ & 1.00 & $450(50.1)$ & 1.00 \\
\hline Not good & $272(28.2)$ & 1.00 & $314(34.9)$ & $1.39(1.13,1.72)$ \\
\hline Don't know & $151(16.6)$ & 1.00 & $135(15.0)$ & $1.08(0.83,1.42)$ \\
\hline Non-parents $(n=1890)$ & $1000(100)$ & & $890(100)$ & \\
\hline Good & $534(53.4)$ & 1.00 & $364(40.9)$ & 1.00 \\
\hline Not good & $297(29.7)$ & 1.00 & $390(43.8)$ & $2.01(1.63,2.47)$ \\
\hline Don't know & 169 (16.9) & 1.00 & $136(15.3)$ & $1.25(0.95,1.64)$ \\
\hline
\end{tabular}

${ }^{1}$ RRR's were estimated using multinomial regression models adjusted for age, gender, ethnicity, parental status, education level, region of the country, income adequacy, self-reported nutrition knowledge, front-of-pack label understanding, use, and influence on purchasing decisions and daily calorie counting Bolds indicate significant $(p<0.05)$ associations 
"healthy" "nutritious" or "that its consumption does not cause adverse effects" [25].

Also, children have been identified as the major influencers within the family decision making unit $[26,27]$. Therefore, other possible explanation to the differences in the effect of cartoon characters between parents and non-parents might be due to actual influences of children preferences on parental decisions but evidence is not consistent among populations. In the UK, $34 \%$ of sales of food are driven by children nagging [28] and $40-80 \%$ of children requests of foods were granted [29]. A study in Scottish parents, showed that they may grant children requests of foods, despite knowing their child's demand was for junk food [30]. Conversely, a study in the UK found that parents claimed not to give in to their children's requests to purchase unhealthy foods [31]. Similarly, in an experiment carried out in Australia, parents were not affected in their food choices by the presence of a cartoon character, regardless of whether the character may have appealed to children or represented a sporting activity, but they counted with the advantage of the Health Star Rating front-of-pack label that was the main contributor of the food choices [32]

In our study, Guideline Daily Allowances, the mandatory front-of-pack label in Mexico, were displayed on the boxes. However, the label was intentionally small to prevent consumers from reading it, thus the label was unlikely to affect the answers. Future studies could explore this relation to clarify the contribution of children preferences to their parents' food selection, considering the effect of cartoon characters displayed in food products directed to children and their effect while front-ofpack labels are displayed along with marketing strategies [33]. Finally, the effect size of the cartoon character found in our study may be considered small. In our study, $29 \%$ of participants in the control group and 39\% in the cartoon character group considered the breakfast cereal as "not good to buy for children", a difference of 10.4 percentage points between groups. This effect was stronger among non-parents (14 percentage points).

To our knowledge, no other study among parents or adults has explored the proportion of participants considering a food product as "good" or "healthy" when a cartoon character is displayed on the front of the pack. Similarly, studies conducted among children have rarely explored the effect of cartoon characters on diet quality perceptions [11]. However, studies among children exploring other outcomes (e.g. food choices) have usually reported larger differences between groups. For example a study among Guatemalan children (4-9 years of age) found that cartoon characters increased the taste preference and snack choices between 20 to 40 percentage points [34]. Taken together, results suggest that while cartoon characters may promote the consumption of specific foods among children [11], an opposite or null effect on healthiness perception is observed among adults and parents.

To our knowledge, this is the first nation-wide study in Latin America evaluating the impact of cartoon characters on perceptions of processed foods. However, our study has limitations that should be acknowledged. First, the sample consisted mostly of participants of high socioeconomic and educational levels with access to internet, as is commonly observed when using internet-based data collection approaches. According to the 2015 National InterCensus Survey, $18.6 \%$ of Mexican population older than 15 years have a university degree or more [35], which is much lower than the $\approx 70 \%$ of participants with this education level in our sample. Considering that in Mexico $50.9 \%$ of households have access to internet [36] and that the average education level is considerably lower to the one reported in this study, the external validity of our findings is limited to those with similar characteristics to the ones of participants. Thus, our findings mostly reflect the effect of cartoon characters on the perceived goodness of breakfast cereals among high income Mexicans.

However, we believe that our results provide important insights for understanding the impact of cartoon characters among high SES groups in Mexico, which until now has been understudied. Another limitation of this study was that we did not assess the impact of a broader range of cartoon characters on adults' perceptions. Cartoon characters are hypothesized to influence food preferences through their familiarity and likability particularly among children. However, this study was unable to recreate the real-world experience of shopping for cereal while considering children's preferences, which influence parental food purchasing behavior $[11,30]$.

\section{Conclusion}

Among this sample of Mexican adults, a cereal with a cartoon character on the packaging was more often perceived as "not good to buy for children" compared to a cereal without the cartoon. This effect was smaller among parents, probably due to children influences of parental decisions during food purchasing. Future studies should continue exploring the effect of this and other marketing strategies used by the food industry among a more diverse population to identify potential strategies that help consumers make informed and healthy choices.

\section{Supplementary information}

Supplementary information accompanies this paper at https://doi.org/10. 1186/s12937-020-00565-5.

Additional file 1: Table S1. Multinomial regression model with interaction between parental status and experimental group $(n=3755)$ 


\section{Acknowledgements}

Not applicable.

\begin{abstract}
Authors' contributions
ACM performed the statistical analysis and wrote the first draft of the manuscript. AJ helped analyze and interpret the data and contributed in preparing the draft; $\mathrm{CN}$ helped in the statistical analysis and to draft the manuscript. MGH, JVM, DIZ, helped draft the manuscript and revised the manuscript for intellectual content. DH conceived, designed and executed the International Food Policy Study and revised the manuscript for intellectual content. SB revised the manuscript for intellectual content. AJ, SB and JT contributed to the preparation of the International Food Policy Study. All authors read and approved the final manuscript.
\end{abstract}

\section{Funding}

Funding for this project was provided by a Population Health Intervention Research operating grant from the Canadian Institutes of Health Research $[\mathrm{ClHR}$ ) and the Public Health Agency of Canada. Additional funding for this project has been provided by a PHAC - CIHR Chair in Applied Public Health [DH). Bloomberg Philanthropies (Grant \#43003) supported ACM's time writing the paper. The funding agencies did not play any role in the design of the study, analysis and interpretation of data and in writing the manuscript.

\section{Availability of data and materials}

The datasets used and/or analyzed during the current study are available from the corresponding author on reasonable request.

\section{Ethics approval and consent to participate}

The study was reviewed by and received ethics clearance through a University of Waterloo Research Ethics Committee [ORE\# 21460). A full description of the study methods can be found in the International Food Policy Study: Technical Report - Wave 1 [2017) at www.foodpolicystudy. com/methods

\section{Consent for publication}

Not applicable.

\section{Competing interests}

The authors declare that they have no competing interests.

\section{Author details}

'Nutrition and Health Research Center, Mexican National Institute of Public Health, Av. Universidad 655 Col, Santa María Ahuacatitlán, 62100 Cuernavaca, Mexico. ${ }^{2}$ Department of Health Behavior, Gillings School of Global Public Health, University of North Carolina, Chapel Hill, NC 27599, USA. ${ }^{3}$ Population Health Research Center, Mexican National Institute of Public Health, Av. Universidad 655 Col. Santa María Ahuacatitlán, 62100 Cuernavaca, Mexico. ${ }^{4}$ Department of Health Promotion, Education \& Behavior, Arnold School of Public Health, University of South Carolina, 921 Assembly St, Columbia, SC 29208, USA. ${ }^{5}$ School of Demography, ANU College of Arts and Social Sciences, The Australian National University, 9 Fellows Road Acton ACT, Canberra 260, Australia.

Received: 2 November 2019 Accepted: 11 May 2020

Published online: 17 May 2020

\section{References}

1. OECD. Obesity Update 2017. Available from: https://www.oecd.org/els/ health-systems/Obesity-Update-2017.pdf.

2. NCD Risk Factor Collaboration (NCD-RisC) Worldwide trends in body-mass index, underweight, overweight, and obesity from 1975 to 2016: a pooled analysis of 2416 population-based measurement studies in 128.9 million children, adolescents, and adults. Lancet. 2017;390(10113):2627-42. https:// doi.org/10.1016/S0140-6736[17)32129-3 Epub 2017 Oct 10.

3. Gakidou E, Ng M, Fleming T, Robinson M, Thomson B, Graetz N, Margono C, Mullany EC, Biryukov S, et al. Global, regional and national prevalence of overweight and obesity in children and adults 1980-2013: A systematic analysis. Lancet. 2014;384(9945):766-81. https://doi.org/10.1016/501406736[14)60460-8.
4. Romieu I, Dossus L, Barquera S, Blottière HM, Franks PW, Gunter M. Energy balance and obesity: what are the main drivers? Cancer Causes Control. 2017;28(3):247-58. https://doi.org/10.1007/s10552-017-0869-z.

5. Hall KD, Ayuketah A, Brychta R, Cai H, Cassimatis T, Chen KY, Chung ST, Costa E, Courville A, Darcey V. Ultra-processed diets cause excess calorie intake and weight gain: A one-month inpatient randomized controlled trial of ad libitum food intake. https://doi.org/10.31232/osf.io/w3zh2.

6. Donin AS, Nightingale CM, Owen CG, Rudnicka AR, Perkin MR, Jebb SA, Stephen AM, Sattar N, Cook DG, Whincup PH. Regular breakfast consumption and type 2 diabetes risk markers in 9- to 10-year-old children in the child heart and health study in England (CHASE): a cross-sectional analysis. PLoS Med. 2014;11(9):e1001703. https://doi.org/10.1371/journal. pmed.1001703.

7. Aburto TC, Pedraza LS, Sánchez-Pimienta TG, Batis C, Rivera JA. Discretionary foods have a high contribution and fruits, vegetables, and legumes have a low contribution to the total energy intake of the Mexican population. J Nutr. 2016;146(Suppl):1881S-7S.

8. Nieto C, Rincon-Gallardo Patiño S, Tolentino-Mayo L, Carriedo A, Barquera S. Characterization of Breakfast Cereals Available in the Mexican Market: Sodium and Sugar Content. Nutrients. 2017;9(8):884. https://doi.org/10.3390/ nu9080884.

9. Afeiche M, Taillie L, Hopkins S, Eldridge A, Popkin B. Breakfast Dietary Patterns among Mexican Children Are Related to Total-Day Diet Quality. J Nutr. 2017;147:239780. https://doi.org/10.3945/jn.116.239780.

10. Connor SM. Food-related advertising on preschool television: Building brand recognition in young viewers. Pediatrics. 2006;1 18(4):1478-85. https:// doi.org/10.1542/peds.2005-2837.

11. Kraak V, Story M. Influence of food companies' brand mascots and entertainment companies' cartoon media characters on children's diet and health: A systematic review and research needs. Obes Rev. 2015;16(2):10726. https://doi.org/10.1016/j.jand.2016.08.012.

12. Ogle AD, Graham DJ, Lucas-Thompson RG, Roberto CA. Influence of Cartoon Media Characters on Children's Attention to and Preference for Food and Beverage Products. J Acad Nutr Diet. 2017;117(2):265-270.e2. https://doi.org/10.1111/obr.12237.

13. Velazquez $\mathrm{CE}$, Pasch KE. Attention to food and beverage advertisements as measured by eyetracking technology and the food preferences and choices of youth. J Acad Nutr Diet. 2014;114:4,578-82. https://doi.org/10.1016/j.jand. 2013.09.030.

14. Hill H, Tilley J. Packaging of children's breakfast cereal: manufacturers versus children. Br Food J. 2002;104:9,766-77. https://doi.org/10.1108/ 00070700210443129

15. McNeal J, Ji M. Children's visual memory of packaging. J Consum Mark. 2003;20:400-27. https://doi.org/10.1108/07363760310489652.

16. Hawkes C. Food packaging: The medium is the message. Public Health Nutr. 2010;13(2):297-9. https://doi.org/10.1017/S1368980009993168.

17. Garretson J, Burton S. The role of Spokescharacters as advertisement and package cues in integrated marketing communications. J Mark. 2005;69. https://doi.org/10.1509/jmkg.2005.69.4.118.

18. The European Consumer Organization. CARTOON CHARACTERS AND FOOD: JUST FOR FUN? Position Paper on the use of brand mascots and licensed media characters in marketing to children. BEUC-X-2017-065 - 13/06/2017. Available at: https://www.beuc.eu/publications/beuc-x-2017-065_eca_ position_paper_on_the_use_of_brand_mascots_and_licensed_media_ characters_in_marketing_to_children.pdf Accessed: October 30, 2019.

19. Sae YW. The Impact of Cartoon Characters and Front-of-Package (FOP) Nutrition Information on Parental Perceptions of Children's Food Products. Thesis project: Waterloo University; 2012. Available at: https://pdfs. semanticscholar.org/4021/0b767f5a6d05b0c1086ab7f34116e3bc78d2.pdf Accessed 30 Oct 2019.

20. Campbell S, James E, Stacey F, Bowman J, Chapman K, Kelly B. A mixedmethod examination of food marketing directed towards children in Australian supermarkets. Health Promot Int. 2014;29:267-77. https://doi.org/ 10.1093/heapro/das060.

21. Gelperowic R, Beharrell B. Healthy food products for children. Br Food J. 1994;96:11,4-8. https://doi.org/10.1108/00070709410074623.

22. Drichoutis A, Lazaridis P, Nayga R. Consumers' use of nutritional labels: a review of research studies and issues. Acad Mark Sci Rev. 2006;10.

23. Sung-Yong K, Rodolfo M, Oral C. Food label use, self-selectivity, and diet quality. J Consum Aff. 2005;35:346-63. https://doi.org/10.1111/j.1745-6606. 2001.tb00118.x. 
24. Burton S, Andrews J. Age, product nutrition, and label format effects on consumer perceptions and product evaluations. J Consum Aff. 1996;30(1): 68-89. https://doi.org/10.1111/j.1745-6606.1996.tb00726.x.

25. Real academia de la lengua española. Definition of "bueno". Available at: https://dle.rae.es/?id=6EawoZ6 Accessed 30 Oct 2019.

26. Clavert S. Children as consumers: advertising and marketing. Spring. 2008; 18(1):205-35. https://doi.org/10.1353/foc.0.0001.

27. Coughlin $R$, Wong $T$. The retail world from a child's perspective. Young Consum. 2003, 4(1):3-8. https://doi.org/10.1108/17473610310813654.

28. Morales E. Children's attitudes to food and drink UK- The nag factor: Measuring children's influence. Mintel International Group Database Admap. 2000;35:35-7.

29. Nicholls A, Cullen P. The child-parent purchase relationship: 'pester power', human rights and retail ethics. J Retail Consum Serv. 2004;11:75-86. https:// doi.org/10.1016/S0969-6989[02)00080-2.

30. Kelly J, Turner J, McKeena K. What parents think: children and healthy eating. Br Food J. 2006;108(5):413-23. https://doi.org/10.1108/ 00070700610661376.

31. Ogba I, Johnson R. How packaging affects the product preferences of children and the buyer behavior of their parents in the food industry. Young Consumers: Insight and ideas for responsible marketers, vol. 11; 2010. p. 77-89. https://doi.org/10.1108/17473611011026037.

32. Russella C, Burkeb P, Waller D, Weib E. The impact of front-of-pack marketing attributes versus nutrition and health information on parents food choices. Appetite, Doi. 116(2017):323-38. https://doi.org/10.1016/j. appet.2017.05.001

33. Cowburn G, Stockley L. Consumer understanding and use of nutrition labelling: a systematic review. Public Health Nutr. 2005;8(1):21-8. https://doi. org/10.1079/PHN2004666.

34. Letona P, Chacon V, Roberto C, et al. Effects of licensed characters on children's taste and snack preferences in Guatemala, a low/middle income country. Int J Obes. 2014;38:1466-9. https://doi.org/10.1038/ijo.2014.38

35. INEGI. Características educativas de la población. Available at: https://www. inegi.org.mx/temas/educacion/default.htm|\#Informacion_general Accessed 30 Oct 2019.

36. INEGI. Tecnologías de la información y comunicaciones. Available at: https:// www.inegi.org.mx/temas/ticshogares/ Accessed 30 Oct 2019.

\section{Publisher's Note}

Springer Nature remains neutral with regard to jurisdictional claims in published maps and institutional affiliations.

Ready to submit your research? Choose BMC and benefit from:

- fast, convenient online submission

- thorough peer review by experienced researchers in your field

- rapid publication on acceptance

- support for research data, including large and complex data types

- gold Open Access which fosters wider collaboration and increased citations

- maximum visibility for your research: over $100 \mathrm{M}$ website views per year

At $\mathrm{BMC}$, research is always in progress.

Learn more biomedcentral.com/submissions 